\title{
Effects of perioperative red blood cell transfusion on systemic immune indicators and postoperative recovery in patients undergoing cesarean section: A propensity score matching analysis
}

Yilu Zhou

Tongji University

Yiyi Tao

Tongji University

Zhendong Xu

Tongji university

Zhiqiang Liu ( $\sim$ eliteromes@126.com )

Shanghai First Maternity and Infant Hospital

Research

Keywords: Blood transfusion, immune indicator, Length of Stay

Posted Date: October 26th, 2021

DOI: https://doi.org/10.21203/rs.3.rs-992187/v1

License: @ (i) This work is licensed under a Creative Commons Attribution 4.0 International License. Read Full License 


\section{Abstract \\ Background}

Postpartum hemorrhage (PPH) is one of the leading causes of maternal death in all regions of the world. Intra-operative red blood cell transfusion is one of the most effective strategies to treat PPH. However, the effect of blood transfusion on patients undergoing cesarean section remains unclear. The aim of this study was to investigate the effects of a intra-operative blood transfusion on systemic immune indicators and postoperative recovery in patients undergoing cesarean section.

\section{Methods}

This retrospective study enrolled patients undergoing cesarean section between January 2016 and June 2020. We divided these patients into two groups according to whether they received a intraoperative blood transfusion. Baseline characteristics were compared between groups. After propensity score matching, the length of stay (LOS), perioperative systemic inflammation-based scores, and postoperative complications were compared. Univariate and multivariable Cox proportional hazard models were used to evaluate the associations between covariates and outcomes.

\section{Results}

A total of 1221 patients were enrolled. After propensity score matching, a significant difference in LOS was observed between groups (4.2days vs. 6.6 days, $P=0.026$ ). The postoperative complication rate in the blood transfusion (BT) group was significantly higher than that in the non-blood transfusion(NBT) group (vomiting, $3.2 \%$ vs. $4.9 \%, P=0.032$; fever, $5.41 \%$ vs. $2.24 \%, P=0.032$; wound complications, $15.44 \%$ vs. $10.45 \%, P=0.028$; intestinal obstructions, $5.88 \%$ vs. $2.75 \%, P=0.034$, respectively). The systemic inflammatory indicators fluctuated significantly in the BT group compared with the NBT group on POD1 and POD3. The multivariate analysis indicated that intra-operative blood transfusion was associated with a longer LOS (hazard ratio: 1.52, 95\% confidence interval: 1.07, 2.25).

\section{Conclusions}

A intra-operative blood transfusion was associated with fluctuations in systemic inflammatory indicators, higher postoperative complication rates and a prolonged length of stay.

\section{Introduction}

Postpartum hemorrhage (PPH) is one of the leading causes of maternal death in all regions of the world, and the definition of PPH is controversial(1). Generally, blood loss of $500 \mathrm{ml}$ or more, blood loss with related physical signs regardless of the mode of delivery, and symptoms of hypovolemia after delivery are considered indicators of PPH(2). In addition, the American College of Obstetricians and Gynecologists (ACOG) issued recommendations that emphasize the importance of an organized and systematic process to help coordinate the response and management of PPH(3). Red blood cell transfusion is one of the most important treatments for PPH(4). However, the effect of intra-operative red blood cell transfusion on postoperative recovery remains unclear.

For patients undergoing cesarean section with bleeding and anemia, blood transfusion can save lives $(5,6)$.Intraoperative strategies for red blood transfusions may affect short-term clinical outcomes in patients undergoing surgery(7). Several retrospective studies have shown that transfused patients have an increased risk of developing infectious and noninfectious postoperative complications after major surgery(8). In addition, the results from a recent randomized controlled trial (RCT) indicate that a restrictive approach in which transfusions were triggered by hemoglobin $(\mathrm{Hb})$ levels lower than $7 \mathrm{~g} / \mathrm{dL}$ increased the risk of postoperative complications.

Furthermore, some studies have found that the infusion of allogeneic blood inhibits the immune function of patients, which is not conducive to improving the prognosis in the perioperative period (9).

The association of intraoperative blood transfusion and postoperative recovery in patients suffering from PPH remains unclear. Additionally, studies examining whether receiving blood transfusion during surgery will promote postoperative complications and the effect of the duration of hospitalization on obstetric patients are still lacking. Therefore, we conducted a retrospective study to assess the association between intraoperative blood transfusion and postoperative recovery in patients undergoing cesarean section. We 
hypothesized that intraoperative blood transfusion is associated with a longer length of stay. Furthermore, we investigated the association between perioperative blood transfusion and perioperative systemic inflammatory indicators, postoperative recovery parameters, postoperative complication rates and readmission rates.

\section{Materials And Methods}

\section{Patients}

Patients who underwent cesarean section at Shanghai First Maternity and Infant Health Hospital from January 2016 to June 2020 were enrolled in this study. This study was reviewed and approved by the Shanghai First Maternity Ethnics Committee (Protocol: \#2020-049). All pregnant women or their relatives signed an informed consent form for research data use before undergoing cesarean section. The exclusion criteria were emergency surgery, twin pregnancy, patients treated with anti-inflammatory drugs or immunosuppressants for more than one month before cesarean section, patients with chronic inflammatory diseases, and incomplete medical records. Pregnancy characteristics, medical history, and operative details were reviewed and recorded.

\section{Primary outcome}

The primary outcome of this study was the LOS. LOS was defined as the interval between the date of surgery and the date of discharge.

\section{Secondary outcome}

Secondary endpoints included perioperative systemic inflammation-based scores (NLR, LMR, and SII). The counts of neutrophils, lymphocytes, monocytes and platelets were recorded three days before surgery (pre-surgery), the first day after surgery (POD1) and the third day after surgery (POD3). NLR was defined as the neutrophil to lymphocyte ratio, LMR was defined as the lymphocyte to monocyte ratio, and SII was defined as neutrophil*platelet/lymphocyte ratio. Postoperative complications, wound complications, ICU admission rates and readmission rates within 30 days were reviewed and recorded.

\section{Anesthesia Care}

Upon entering the operating room, pregnancy was monitored according to the American Society of Anesthesiologists (ASA) monitoring standards. Spinal anesthesia was the first choice for all cesarean sections in patients without contraindications. Patients were placed in the right recumbent position and punctured in L3-L4 or L2-L3 space. After observing the free flow of the cerebrospinal fluid after subarachnoid puncture, $0.5 \%$ hyperbaric ropivacaine ( $2 \mathrm{~mL}$ of $0.75 \%$ hyperbaric ropivacaine and $1 \mathrm{~mL}$ of $10 \%$ glucose) was administered. An epidural indwelling catheter with a length of $4 \mathrm{~cm}$ was used in the epidural space. Five minutes later, the anesthetic plane was evaluated at the T4-T6 level. When the effect was not satisfactory, $5 \mathrm{ml}$ of $0.5 \%$ ropivacaine were injected into the epidural space. When the patient presented with contraindications to spinal anesthesia (coagulation dysfunction, lumbar disease, shock, etc.), general anesthesia was administered. General anesthesia was induced with propofol (target-controlled infusion, effect-site concentration: $3.0-4.0 \mu \mathrm{g} / \mathrm{ml})$, remifentanil $(0.3-0.5 \mu \mathrm{g} / \mathrm{kg})$, and rocuronium $(0.6 \mathrm{mg} / \mathrm{kg})$. The patients were then endotracheally intubated, and general anesthesia was maintained with propofol, sufentanil and remifentanil. Repeated bolus injections of sufentanil and rocuronium were administered as necessary throughout the operation.

\section{Statistical Analysis}

We compared different clinical factors between the blood transfusion group and the non-blood transfusion group. Descriptive statistics, including the means and standard deviations, were reported for continuous variables. Frequency counts and percentages were calculated for categorical variables such as the ASA physical status, gestational age at delivery, birthweight, operation time, blood loss, and pre-Hgb levels. Univariate Cox proportional hazards models were fitted to evaluate the effects of continuous variables on time-to-event outcomes. Multivariable Cox proportional hazard models were used for the multivariate analysis to include important and significant covariates. We performed a propensity score matching analysis to reduce selection bias by building a matched group of patients to compare LOS between patients with a blood transfusion and those without a blood transfusion. Patients were matched using a 5-to-1 digit greedy match algorithm. Statistical analyses were performed with SPSS version 17.0 (SPSS Inc., Chicago, IL, USA). $\mathrm{P}<0.05$ was considered statistically significant.

\section{Results}


A total of 1426 patients who underwent cesarean section were enrolled in this study. After reviewing the exclusion criteria, 329 patients were included in the BT group, and 909 were included in the NBT group (Figure 1). After propensity score matching, no significant differences in age $(P=0.139)$, BMI $(P=0.526)$, ASA status $(P=0.811)$, gestational age at delivery $(P=0.363)$, birthweight $(P=0.262)$, primary mode of anesthesia $(P=0.893)$, primary cause of $\mathrm{PPH}(\mathrm{P}=0.993)$, and experience of the attending obstetrician $(P=0.878)$ were observed between groups. However, significant differences in the operation time $(P<0.001)$, blood loss $(P<0.001)$ and pre-Hgb levels $(P<0.001)$ were identified (Table 1).

\section{Primary outcome}

The LOS was defined as the date of surgery to the date of discharge. The LOS in the NBT group was significantly shorter than that in the BT group (mean time (days): 4.2 vs. $7.1, P=0.026$,Fig. $2 A$ ).

\section{Secondary outcome}

Regarding postoperative complications, the incidence of postoperative vomiting was higher in the BT group than in the NBT group ( $3.2 \%$ vs. $4.9 \%, P=0.032$,Fig. $2 B$ ). The incidence of postoperative fever was higher in the BT group than in the NBT group ( $5.41 \%$ vs. $2.24 \%, P=0.032$,Fig. $2 B$ ). For postoperative pneumonia, no significant differences were observed between the two groups ( $3.2 \%$ vs. $3.4 \%, P=0.563$,Fig. 2B). Furthermore, the incidence of wound complications in the BT group was higher than that in the NBT group $(15.44 \%$ vs. $10.45 \%, P=0.028$,Fig. $2 B$ ). The incidence of intestinal obstructions in the BT group was significantly higher than that in the NBT group (5.88\% vs. $2.75 \%, P=0.034$,Fig. $2 B$ ). However, the NBT group had significantly lower 30 -day and ICU admission rates than the $\mathrm{BT}$ group $(4.40 \%$ vs. $7.14 \%, 1.70 \%$ vs. $4.10 \%, \mathrm{P}=0.018$ and $\mathrm{P}=0.034$, respectively,Fig. $2 \mathrm{C})$. According to the univariate analysis, birthweight, a longer operation time, low pre-Hb levels and blood transfusion were associated with a longer LOS. The multivariable analysis showed that birthweight, operation time, low pre-Hb levels and blood transfusion were associated with a longer LOS. After matching, blood transfusion was still associated with a longer LOS.

After matching, no significant differences in the preoperative NLR, LMR or SIl were observed between the two groups (Fig. 3). Compared with preoperative assessments, the NLR and SII in the two groups increased significantly and the LMR was significantly decreased in all patients on POD1 and POD3 ( $\mathrm{P}<0.001$, Fig. $3 B$ ). The NLR and SIl values were slightly lower on POD3 than on POD1 but were still higher than the preoperative values $(P<0.001$, Fig. 3A-C). The NLR and SIl values in the NBT group on POD1 and POD3 were significantly lower than those in the BT group $(P<0.001$, Fig. $2 A-C)$, whereas a significantly higher LMR was detected in the NBT group than in the BT group $(P<0.001$, Fig. 3B).

\section{Discussion}

In this large retrospective cohort study, our results showed that the hospital stay of patients who received a blood transfusion was significantly longer, the incidence of postoperative vomiting and wound complications was higher than that of patients without a blood transfusion, and the postoperative inflammatory index fluctuated more drastically in patients who received a blood transfusion.

The main bleeding site in postpartum hemorrhage is the uterus(10). When postpartum hemorrhage occurs, the uterine muscle tissue is hypoxic and does not contract well, and the sensitivity of oxytocin receptors decreases. Repeated hemostasis operations increase further damage to the uterine muscles(10). At the same time, the sinusoids on the dissected surface of the placenta cannot be closed, and fibrinogen deposition and thrombosis do not play a role(10). Therefore, obstetric hemorrhage has the characteristics of a fast speed, large volume, difficult evaluation, and difficulty of stopping bleeding quickly.

Blood transfusion is the most common method for the clinical treatment of patients with obstetric hemorrhage. It effectively solve the patient's anemia caused by excessive blood loss, helps maintain blood volume and blood pressure, exerts a certain preventive effect on patients with shock, and improves the prognosis of patients $(11,12)$. However, a large number of clinical practices have found that after patients with obstetric hemorrhage receive a large transfusion of blood, although their life and safety are guaranteed, they also experience certain side effects, mainly manifested as abnormal blood coagulation(13). Due to the long-term storage of blood, platelets and coagulation factors are destroyed to a certain extent. After entering the patient's body, the active coagulation factors will be reduced, which will lead to coagulation dysfunction.

In terms of postoperative complications, a large number of allogeneic blood transfusions will significantly increase the incidence of postoperative complications, such as blood transfusion-related lung injury (14) and surgical site infections (15). In the present study,

Page $4 / 11$ 
the incidence of postoperative complications in patients receiving blood transfusion increased significantly during the perioperative period. Zhang et al reported that a perioperative blood transfusion potentially increases the risk of postoperative complications and is associated with a prolonged LOS(9). Furthermore, another study reported that perioperative blood transfusion may be associated with worse outcome in patients undergoing surgery(16). After blood transfusion, the immune system changes significantly. These changes have been shown to be potential mechanisms that increase the risk of infection, graft-versus-host disease and postoperative complications after blood transfusion(17). According to recent studies, the suppression of perioperative immune function may promote postoperative metastasis and recurrence in patients with cancer(18). A large number of studies have also shown that certain markers of blood components, such as NLR, LMR and SII, comprehensively indicate the balance of the host immune system and have been considered indicators related to the prognosis $(19,20)$. An increased NLR or SIl and decreased LMR are associated with a poor prognosis in patients undergoing surgery $(21,22)$. Based on our results, patients undergoing a blood transfusion exhibit greater fluctuations in these systemic inflammatory markers after surgery. Thus, blood transfusion is related to the strong suppression of immune function and/or inflammatory response disorders, such as a higher complication rate and longer hospital stay, in patients receiving a blood transfusion. (23)

Our research has limitations. The limitations include the following: the study was a retrospective study rather than a random controlled trial, and the data were obtained from a single center. Second, even if we perform a propensity score matching analysis, considering the various factors related to postpartum hemorrhage, we still cannot avoid the possibility of biased results due to unmeasured confounding factors.

\section{Conclusion}

In summary, the transfusion of a large amount of blood can save the life and ensure the safety of patients with PPH, but it will exert certain effects on the levels of inflammatory factors and postoperative recovery of the patients. During the treatment period, clinicians should focus on actively implementing measures to avoid risks, prevent complications, and improve patients' long-term prognoses.

\section{Abbreviations}

$\mathrm{PPH}$

Postpartum hemorrhage

LOS

length of stay

BT

blood transfusion

$\mathrm{Hb}$

hemoglobin

NLR

neutrophil to lymphocyte ratio

LMR

lymphocyte to monocyte ratio

SII

System immune indicator

\section{Declarations}

\section{Anknowledgements:None}

\section{Author Contributions}

ZYL, and TYY: conception and design. LZQ,XZD: acquisition, statistical analysis, or interpretation of the data. All authors: drafting of the manuscript, reviewed, and approved the final version of the manuscript. 


\section{Funding}

None

\section{Data Availability Statement}

The raw data supporting the conclusions of this article will be made available by the authors, without undue reservation.

\section{Ethics approved consent to participate}

The studies involving human participants were reviewed and approved by the Shanghai First Maternity Ethnics Committee (Protocol: \#2020-049). Written informed consent for participation was required for this study in accordance with the national legislation and the institutional requirements.

\section{Consent for publication:Not applicable}

Informed consent:Informed consent was obtained from all individuals participants included in the study

Competing Interest:None

\section{References}

1. Shaylor R, Weiniger CF, Austin N, Tzabazis A, Shander A, Goodnough LT, Butwick AJ. National and International Guidelines for Patient Blood Management in Obstetrics: A Qualitative Review. Anesth Analg. 2017 Jan;124(1):216-32. 10.1213/ANE.0000000000001473.. ; ). doi.

2. Nathan LM. An overview of obstetric hemorrhage. Semin Perinatol. 2019 Feb;43(1):2-4. 10.1053/j.semperi.2018.11.001.. ; ). doi.

3. Quantitative Blood Loss in Obstetric Hemorrhage. ACOG COMMITTEE OPINION SUMMARY, Number 794. Obstet Gynecol. 2019 Dec;134(6):1368-9. 10.1097/AOG.0000000000003565.. ; ). doi.

4. O'Brien KL, Shainker SA, Lockhart EL. Transfusion Management of Obstetric Hemorrhage. Transfus Med Rev. 2018 Oct;32(4):24955. 10.1016/j.tmrv.2018.05.003.. ; ). doi.

5. Muñoz M, Stensballe J, Ducloy-Bouthors AS. et al. Patient blood management in obstetrics: prevention and treatment of postpartum haemorrhage. A NATA consensus statement. Blood Transfus. 2019;17(2):112-36. 10.2450/2019.0245-18.. ; ). doi.

6. Sultan I, Bianco V, Brown JA, Kilic A, Harbertheuer A, Aranda-Michel E, Navid F, Humar R, Wang Y, Gleason TG. The long-term impact of perioperative red blood transfusion on patients undergoing cardiac surgery. Ann Thorac Surg. 2020 Nov 7:S00034975(20)31886-5. doi: 10.1016/j.athoracsur.2020.10.023.

7. Kim T, Purdy MP, Kendall-Rauchfuss L, Habermann EB, Bews KA, Glasgow AE, Khan Z. Myomectomy associated blood transfusion risk and morbidity after surgery. Fertil Steril. 2020 Jul;114(1):175-84. 10.1016/j.fertnstert.2020.02.110.. ; ). doi.

8. Connor JP, O'Shea A, McCool K, Sampene E, Barroilhet LM. Peri-operative allogeneic blood transfusion is associated with poor overall survival in advanced epithelial ovarian Cancer; potential impact of patient blood management on Cancer outcomes. Gynecol Oncol. 2018 Nov;151(2):294-8. 10.1016/j.ygyno.2018.08.040.. ; ). doi.

9. Zhang H, Wu X, Xu Z, Sun Z, Zhu M, Chen W, Miao C. Impact of perioperative red blood cell transfusion on postoperative recovery and long-term outcome in patients undergoing surgery for ovarian cancer: A propensity score-matched analysis. Gynecol Oncol. 2020 Feb;156(2):439-45. 10.1016/j.ygyno.2019.12.006.. ;). doi.

10. Andrikopoulou M, D'Alton ME. Postpartum hemorrhage: early identification challenges. Semin Perinatol. 2019 Feb;43(1):11-7. 10.1053/j.semperi.2018.11.003.. ; ). doi.

11. Surbek D, Vial Y, Girard T, Breymann C, Bencaiova GA, Baud D, Hornung R, Taleghani BM, Hösli I. Patient blood management (PBM) in pregnancy and childbirth: literature review and expert opinion. Arch Gynecol Obstet. 2020 Feb;301(2):627-41. 10.1007/s00404019-05374-8. Epub 2019 Nov 14.. ; ). doi. 
12. Zdanowicz JA, Schneider S, Mueller M, Tschudi R, Surbek D. Red blood cell transfusion in obstetrics and its implication for patient blood management: a retrospective analysis in Switzerland from 1998 to 2016. Arch Gynecol Obstet. 2021 Jan;303(1):121-8. 10.1007/s00404-020-05744-7.. ; ). doi.

13. Thurn L, Wikman A, Westgren M, Lindqvist PG. Massive blood transfusion in relation to delivery: incidence, trends and risk factors: a population-based cohort study. BJOG. 2019 Dec;126(13):1577-86. 10.1111/1471-0528.15927.. ; ). doi.

14. Semple JW, Rebetz J, Kapur R. Transfusion-associated circulatory overload and transfusion-related acute lung injury. Blood. 2019 Apr 25;133(17):1840-1853. doi: 10.1182/blood-2018-10-860809.

15. Yuan Y, Zhang Y, Shen L, Xu L, Huang Y. Perioperative Allogeneic Red Blood Cell Transfusion and Wound Infections: An Observational Study. Anesth Analg. 2020 Nov;131(5):1573-81. 10.1213/ANE.0000000000005122.. ; ). doi.

16. Owusu-Agyemang P, Zavala AM, Williams UU. Van Meter A, Soliz J, Kapoor R, Shah A, Hernandez M, Gottumukkala V, Cata JP. Assessing the impact of perioperative blood transfusions on the survival of adults undergoing cytoreductive surgery with hyperthermic intraperitoneal chemotherapy for appendiceal carcinomatosis. Vox Sang. 2017 Aug;112(6):567-77. doi: 10.1111/vox.12546.

17. Papageorge CM, Kennedy GD, Carchman EH. Preoperative blood transfusion is a predictor of worse short-term postoperative outcomes after colectomy. Surgery. 2017 Apr,161(4):1067-1075. doi: 10.1016/j.surg.2016.08.042.

18. Tai LH, Alkayyal AA, Leslie AL, Sahi S, Bennett S, Tanese de Souza C, Baxter K, Angka L, Xu R, Kennedy MA, Auer RC. Phosphodiesterase-5 inhibition reduces postoperative metastatic disease by targeting surgery-induced myeloid derived suppressor cell-dependent inhibition of Natural Killer cell cytotoxicity. Oncoimmunology. 2018 Mar 1;7(6):e1431082. doi: 10.1080/2162402X.2018.1431082.

19. Selvaggio S, Abate A, Brugaletta G, Musso C. Di Guardo M, Di Guardo C, Vicari ESD, Romano M, Luca S, Signorelli SS. Platelettolymphocyte ratio, neutrophiltolymphocyte ratio and monocytetoHDL cholesterol ratio as markers of peripheral artery disease in elderly patients. Int J Mol Med 2020 Sep;46(3):1210-6. doi: 10.3892/ijmm.2020.4644.

20. Selvaggio S, Abate A, Brugaletta G, Musso C. Di Guardo M, Di Guardo C, Vicari ESD, Romano M, Luca S, Signorelli SS. Platelettolymphocyte ratio, neutrophiltolymphocyte ratio and monocytetoHDL cholesterol ratio as markers of peripheral artery disease in elderly patients. Int J Mol Med 2020 Sep;46(3):1210-6. doi: 10.3892/ijmm.2020.4644.

21. Hirahara T, Arigami T, Yanagita S, Matsushita D, Uchikado Y, Kita Y, Mori S, Sasaki K, Omoto I, Kurahara H, Maemura K, Okubo K, Uenosono Y, Ishigami S, Natsugoe S. Combined neutrophil-lymphocyte ratio and platelet-lymphocyte ratio predicts chemotherapy response and prognosis in patients with advanced gastric cancer. BMC Cancer. 2019 Jul 8;19(1):672. doi: 10.1186/s12885-0195903-y..

22. Zhang LX, Wei ZJ, Xu AM, Zang JH. Can the neutrophil-lymphocyte ratio and platelet-lymphocyte ratio be beneficial in predicting lymph node metastasis and promising prognostic markers of gastric cancer patients? Tumor maker retrospective study. Int J Surg. 2018 Aug;56:320-7. 10.1016/j.ijsu.2018.06.037.. ,. doi.

23. Nizri E, Kusamura S, Fallabrino G, Guaglio M, Baratti D, Deraco M. Dose-Dependent Effect of Red Blood Cells Transfusion on Perioperative and Long-Term Outcomes in Peritoneal Surface Malignancies Treated with Cytoreduction and HIPEC. Ann Surg Oncol. 2018 Oct;25(11):3264-70. 10.1245/s10434-018-6630-3.. ; ). doi.

\section{Tables}

Table1. Baseline characteristics in BT group and NBT group 


\begin{tabular}{|c|c|c|c|c|c|c|c|}
\hline & \multicolumn{2}{|l|}{ Original cohort } & \multirow[t]{2}{*}{$P$} & \multicolumn{2}{|l|}{ Matched cohort } & \multirow[t]{2}{*}{$P$} & \multirow{2}{*}{$\begin{array}{l}\text { Standard } \\
\text { difference } \\
\text { ॠ\%区 }\end{array}$} \\
\hline & BT group $(n=312)$ & $\begin{array}{l}\text { NBT } \\
\text { group }(n=909)\end{array}$ & & BT group $(n=312)$ & $\begin{array}{l}\text { NBT } \\
\text { group }(n=312)\end{array}$ & & \\
\hline Age (years) & $33.49 \pm 4.51$ & $32.97 \pm 4.23$ & 0.066 & $33.49 \pm 4.51$ & $32.97 \pm 4.26$ & 0.139 & 3.52 \\
\hline $\begin{array}{l}\text { BMI } \\
(\mathrm{kg} / \mathrm{m} 2)\end{array}$ & $27.5(23.5-35.3)$ & $26.0(21.7-33.6)$ & 0.425 & $27.5(23.5-35.3)$ & $26.0(20.7-32.6)$ & 0.526 & 2.44 \\
\hline ASA & & & & & & & 1.98 \\
\hline$I-I I$ & $273(87.5 \%)$ & $842(92.6 \%)$ & 0.005 & $273(87.5 \%)$ & $271(86.9 \%)$ & 0.811 & \\
\hline III & $39(12.5 \%)$ & $67(7.4 \%)$ & & $39(12.5 \%)$ & $41(13.1 \%)$ & & \\
\hline $\begin{array}{l}\text { Gestational } \\
\text { age at } \\
\text { delivery } \\
\text { (days) }\end{array}$ & $273.11 \pm 22.11$ & $272.66 \pm 20.66$ & 0.745 & $273.11 \pm 22.11$ & $274.66 \pm 20.36$ & 0.363 & \\
\hline $\begin{array}{l}\text { Birthweight } \\
\text { (g) }\end{array}$ & $3488.31 \pm 1006.69$ & $3073.16 \pm 1078.84$ & $<0.001$ & $3488.31 \pm 1006.69$ & $3423.16 \pm 1086.85$ & 0.262 & 2.56 \\
\hline $\begin{array}{l}\text { Primary } \\
\text { Mode of } \\
\text { Anesthesia }\end{array}$ & & & 0.192 & & & 0.893 & 4.42 \\
\hline General & $31(10 \%)$ & $69(7.6 \%)$ & & $31(10 \%)$ & $30(9.6 \%)$ & & \\
\hline Neuraxial & $281(90 \%)$ & $840(92.4 \%)$ & & $281(90 \%)$ & $282(90.4 \%)$ & & \\
\hline $\begin{array}{l}\text { Primary } \\
\text { cause of } \\
\text { PPH }\end{array}$ & & & 0.987 & & & 0.993 & \\
\hline $\begin{array}{l}\text { Uterine } \\
\text { atony }\end{array}$ & $128(41 \%)$ & $378(41.8 \%)$ & & $128(41.0 \%)$ & $127(40.8 \%)$ & & \\
\hline $\begin{array}{l}\text { Placenta } \\
\text { accreta }\end{array}$ & $70(22.4 \%)$ & $195(21.5 \%)$ & & $70(22.4 \%)$ & $68(21.9 \%)$ & & \\
\hline $\begin{array}{l}\text { Retained } \\
\text { placenta }\end{array}$ & $102(32.6 \%)$ & $300(33 \%)$ & & 102(32.6\%) & 104(33.2\%) & & \\
\hline Others & $12(4 \%)$ & $36(3.7 \%)$ & & $12(4 \%)$ & $13(4.1 \%)$ & & \\
\hline $\begin{array}{l}\text { Operation } \\
\text { time(min) }\end{array}$ & $55.20 \pm 8.54$ & $42.64 \pm 7.83$ & $<0.001$ & $55.20 \pm 8.54$ & $40.64 \pm 7.13$ & $<0.001$ & 6.58 \\
\hline $\begin{array}{l}\text { Blood } \\
\text { Loss(ml) }\end{array}$ & $831.65 \pm 78.35$ & $241.39 \pm 83.61$ & $<0.001$ & $831.65 \pm 78.35$ & $236.39 \pm 80.21$ & $<0.001$ & 7.45 \\
\hline $\begin{array}{l}\text { Pre Hgb } \\
\text { [g/dla }\end{array}$ & $101.72 \pm 33.28$ & $119.67 \pm 25.33$ & $<0.001$ & $101.72 \pm 33.28$ & $112.67 \pm 45.33$ & $<0.001$ & 7.98 \\
\hline $\begin{array}{l}\text { Experience } \\
\text { of attending } \\
\text { obstetrician }\end{array}$ & & & & & & & 3.14 \\
\hline$\nabla 5$ years & $28(9 \%)$ & $69(7.6 \%)$ & 0.427 & $28(9 \%)$ & $27(8.6 \%)$ & 0.878 & \\
\hline $\begin{array}{l}5 \text { years or } \\
\text { more }\end{array}$ & 283(91\%) & $840(92.4 \%)$ & & 283(91\%) & $285(91.4 \%)$ & & \\
\hline
\end{tabular}

Abbreviations: BMI: Body Mass Index; IQR: Inter Quartile Range; ASA: American Society of Anesthesiologists score; PPH: Postpartum haemorrhage

Table 2. Univariate analysis Length Of Stay 


\begin{tabular}{|c|c|c|c|c|c|c|c|}
\hline \multirow[t]{2}{*}{ Variables } & \multicolumn{2}{|l|}{ LOS } & \multicolumn{5}{|c|}{ Table 3. Multivariable Cox proportional of LOS } \\
\hline & $\mathrm{HR}(95 \% \mathrm{Cl})$ & $P$-value & \multirow[t]{3}{*}{ Variables } & \multicolumn{2}{|c|}{ LOS (Before matching) } & \multicolumn{2}{|c|}{ LOS (After matching) } \\
\hline Age (years) & $1.02(0.98,1.21)$ & 0.258 & & \multirow[t]{2}{*}{$\mathrm{HR}(95 \% \mathrm{Cl})$} & \multirow{2}{*}{$\begin{array}{l}P \text { - } \\
\text { value }\end{array}$} & \multirow[t]{2}{*}{$\mathrm{HR}(95 \% \mathrm{Cl})$} & \multirow{2}{*}{$\begin{array}{l}P- \\
\text { value }\end{array}$} \\
\hline BMI (kg/m2) & $1.11(0.72,1.52)$ & 0.324 & & & & & \\
\hline ASA & $1.05(0.70,1.46)$ & 0.159 & Birthweight & $1.73(1.10,2.40)$ & 0.034 & 1.65(1.06,2.32) & 0.019 \\
\hline Gestational age at delivery & $1.15(0.64,1.20)$ & 0.267 & $\begin{array}{l}\text { Operation } \\
\text { time(min) }\end{array}$ & $1.60(1.13,1.76)$ & 0.012 & $1.51(1.13,1.61)$ & 0.042 \\
\hline Birthweight & $2.10(1.71,2.76)$ & $<0.001$ & Pre Hgb & $1.51(1.01,1.98)$ & $<0.001$ & $1.42(1.02,1.78)$ & 0.045 \\
\hline Operation time(min) & $1.52(1.24,1.75)$ & $<0.001$ & \multirow{2}{*}{$\begin{array}{l}\text { Blood } \\
\text { transfusion }\end{array}$} & \multirow[t]{2}{*}{$1.93(1.03,2.45)$} & \multirow[t]{2}{*}{0.004} & \multirow[t]{2}{*}{$1.52(1.07,2.25)$} & \multirow[t]{2}{*}{0.024} \\
\hline Pre Hgb & $1.45(0.93,1.71)$ & 0.254 & & & & & \\
\hline Pre Hct & $1.42(1.29,1.58)$ & $<0.001$ & \multirow{3}{*}{ Figures } & & & & \\
\hline Experience of obstetrician & $1.12(0.94,1.46)$ & 0.078 & & & & & \\
\hline Blood transfusion & $1.56(1.15,1.98)$ & 0.032 & & & & & \\
\hline
\end{tabular}

A

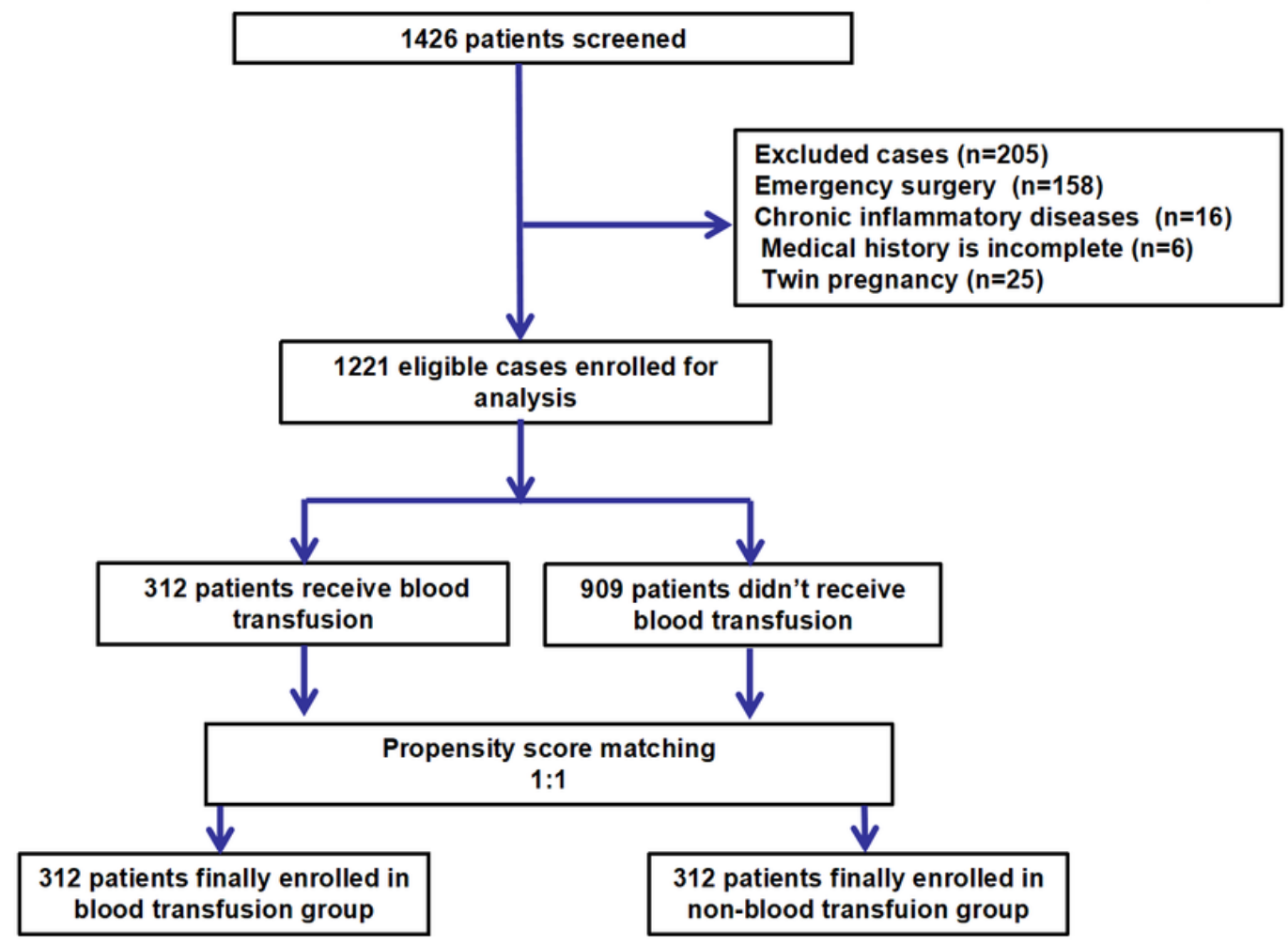

Figure.1

Figure 1

Flowchart of patients enrolled in the study 
A

Length of Stay

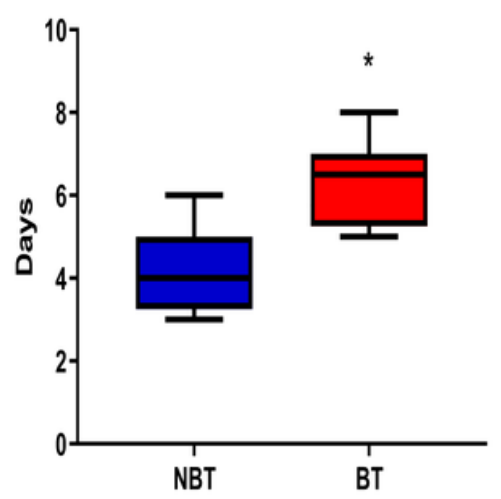

B

Postoperative Complications

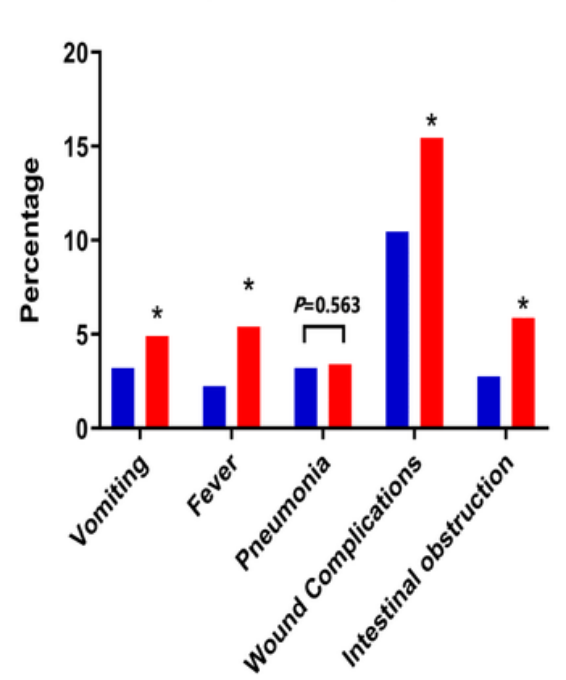

C

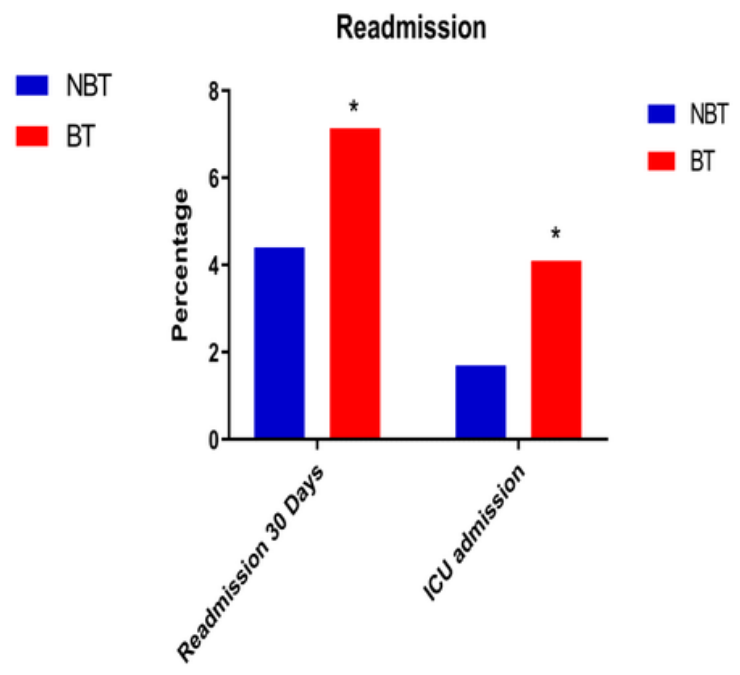

\section{Figure.2}

\section{Figure 2}

Primary outcome of the study.(A).Length of Stay,(B).Postoperative complication,(C) Readmission rate between the groups. 

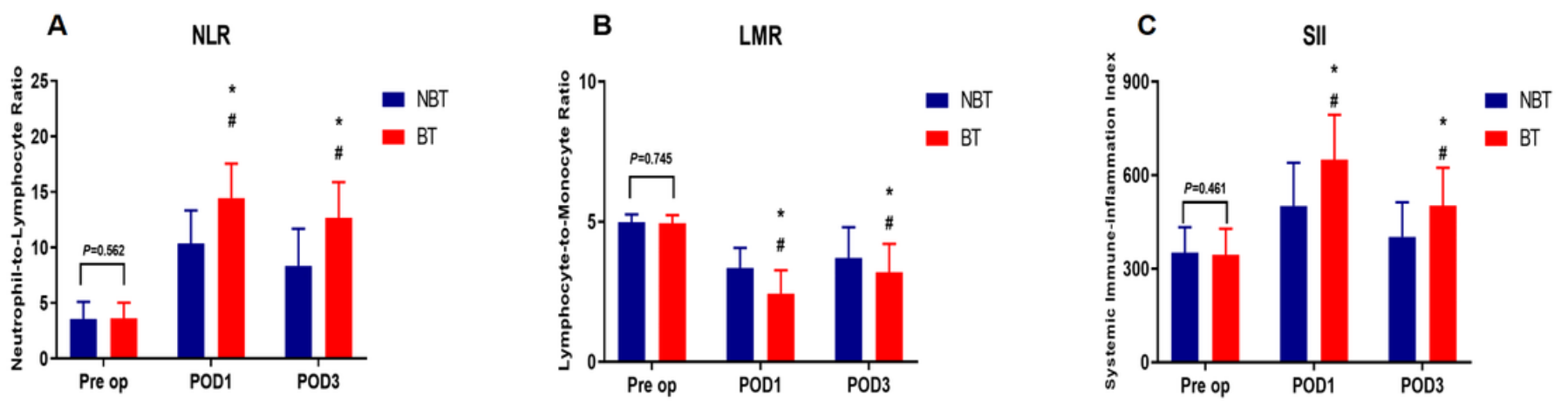

\section{Figure.3}

\section{Figure 3}

Perioperative System immune indicators.(A),NLR, (B)LMR, (C) SII 